\title{
Characteristics of the surface ruptures associated with the 2016 Kumamoto earthquake sequence, central Kyushu, Japan
}

\author{
Yoshiki Shirahama1*, Masayuki Yoshimi', Yasuo Awata', Tadashi Maruyama', Takashi Azuma', Yukari Miyashita', \\ Hiroshi Mori ${ }^{2}$, Kazutoshi Imanishi ${ }^{1}$, Naoto Takeda ${ }^{1}$, Tadafumi Ochi ${ }^{1}$, Makoto Otsubo ${ }^{1}$, Daisuke Asahina ${ }^{1}$ \\ and Ayumu Miyakawa ${ }^{1}$
}

\begin{abstract}
The 2016 Kumamoto earthquake sequence started with a $M_{j}$ (Japan Meteorological Agency magnitude) 6.5 event on April 14, and culminated in a $M_{\mathbf{J}} 7.3$ event on April 16. Associated with the sequence, approximately $34-\mathrm{km}$-long surface ruptures appeared along the eastern part of the Futagawa fault zone and the northernmost part of the Hinagu fault zone. We carried out an urgent field investigation soon after the earthquake to map the extent and displacement of surface ruptures with the following results. (1) The rupture zone generally consisted of a series of left-stepping en echelon arrays of discontinuous fault traces of various lengths. (2) Slip exceeding $100 \mathrm{~cm}$ occurred on previously unrecognized fault traces in the alluvial lowland of the Kiyama plain and on the western rim of the Aso volcano caldera. (3) Large slip with maximum dextral slip of $220 \mathrm{~cm}$ was measured throughout the central section of the rupture zone along the Futagawa segment, and the slip gradually decreased bilaterally on the adjoining northeastern and southwestern sections. (4) The surface rupture mostly occurred along fault traces mapped in previous active fault investigations. (5) Most of the surface ruptures were produced by the mainshock, and significant postseismic slip occurred after the mainshock.
\end{abstract}

Keywords: 2016 Kumamoto earthquake surface rupture, Futagawa fault zone, Hinagu fault zone, Slip distribution, Urgent field investigation

\section{Introduction}

The 2016 Kumamoto earthquake was a series of shallow earthquakes in central Kyushu, Japan, that started with a $M_{\mathrm{J}}$ (Japan Meteorological Agency magnitude) 6.5 event at 21:26 Japan Standard Time on April 14 and included the $M_{\mathrm{J}} 7.3$ mainshock at 01:26 on April 16 (Fig. 1a). These earthquakes caused severe damage to houses and infrastructure in the epicentral region, especially in the communities of Mashiki, Nishihara, and Minamiaso in Kumamoto Prefecture, where instrumental ground motions reached the maximum level of 7 on the Japan Meteorological Agency seismic intensity scale. This

\footnotetext{
*Correspondence: y.shirahama@aist.go.jp

${ }^{1}$ Geological Survey of Japan, National Institute of Advanced Industrial

Science and Technology, 1-1-1 Higashi, Tsukuba 305-8567, Japan

Full list of author information is available at the end of the article
}

sequence occurred mainly along the active Futagawa and Hinagu fault zones (Earthquake Research Committee, the Headquarters for Earthquake Research Promotion (hereinafter refer to as ERC, HERP), 2016a, b) (Fig. 1b).

We began an urgent field investigation on the day of the mainshock to map coseismic ruptures and measure their displacements. This three-week exercise documented approximately $34 \mathrm{~km}$ of surface ruptures associated with the 2016 Kumamoto earthquake sequence. The ruptures occurred mainly on the eastern part of the Futagawa fault zone, an eastern extension of the Futagawa fault zone across the western rim of the caldera of Aso volcano, and the northernmost part of the Hinagu fault zone (Fig. 1c). We surveyed offset artificial and natural features at more than 200 places. In addition, we interviewed local residents and measured faulted features repeatedly to investigate postseismic activity of the surface ruptures. 


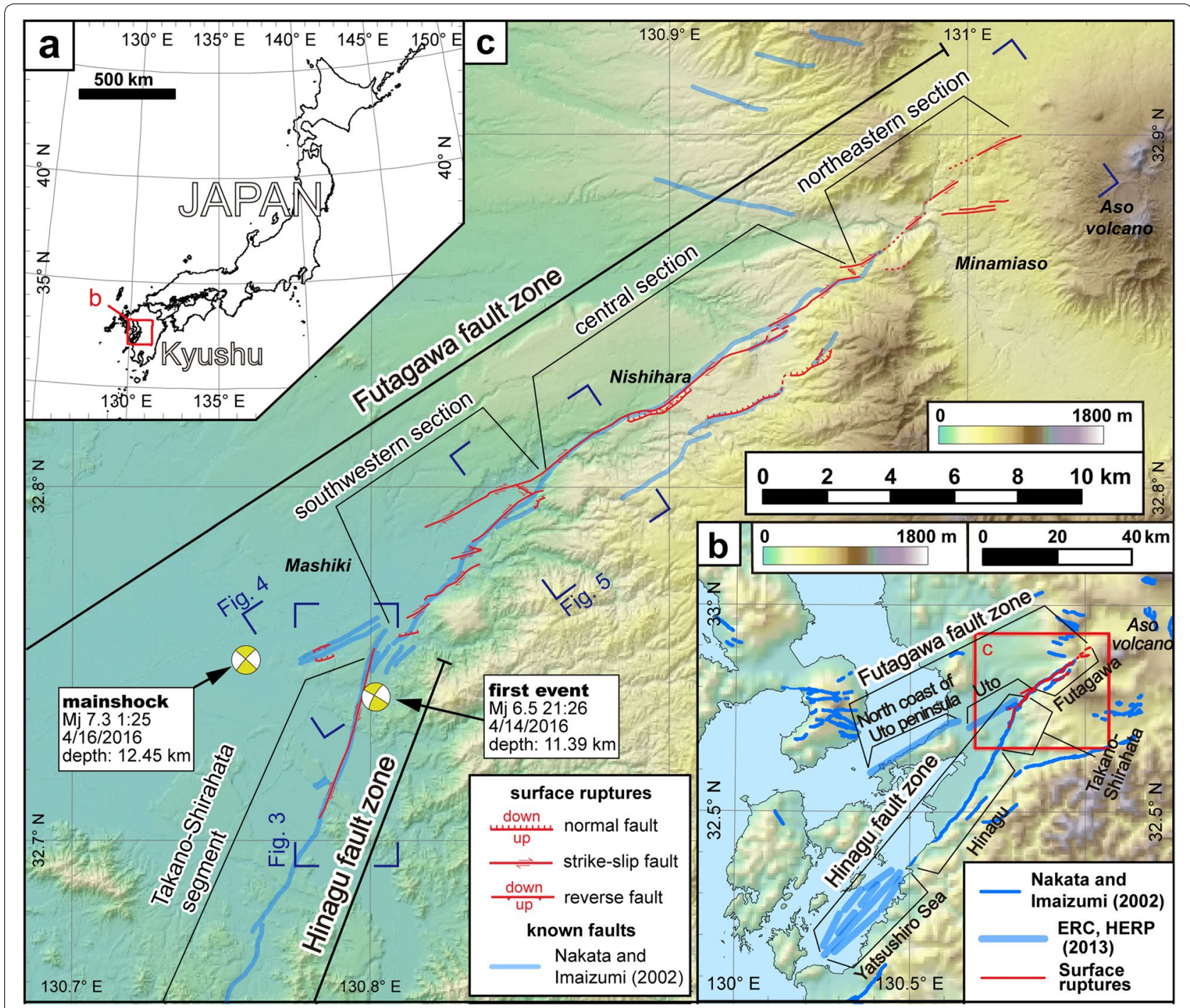

Fig. 1 a Location of the study area in Kyushu, southwestern Japan. b Active faults in the western part of central Kyushu (blue lines after Nakata and Imaizumi 2002, light blue lines after ERC, HERP 2013) and the 2016 surface ruptures (red lines). c Distribution of surface ruptures associated with the 2016 Kumamoto earthquake sequence observed during our survey (red lines), previously mapped active faults (blue lines), and the best doublecouple solution of centroid moment tensor diagrams for the mainshock and the initial $M, 6.5$ event (yellow beach balls) determined by the Japan Meteorological Agency, and unconfirmed ruptures interpreted from aerial photographs (Geospatial Information Authority of Japan 2016c) (dashed red lines)

In this paper, we report the distribution and morphology of surface ruptures and their displacements. We then discuss their active tectonic implications.

\section{Outline of the Futagawa and Hinagu fault zones}

The Futagawa fault zone extends ENE-WSW between the Aso caldera and the north coast of the Uto Peninsula, and the Hinagu fault zone extends NE-SW between Mashiki and the south end of the Yatsushiro Sea (Fig. 1b). These were defined as separate seismogenic fault zones by ERC, HERP (2013) with the following characteristics. The Futagawa fault zone consists of three segments:
Futagawa, Uto, and the north coast of the Uto Peninsula segments (Fig. 1b). The Futagawa segment has $0.2 \mathrm{~m} / \mathrm{kyr}$ of dextral long-term slip rate and $0.1-0.3 \mathrm{~m} /$ kyr of vertical long-term slip rate, and paleoseismological studies indicate that its latest rupture event occurred 2200-6900 years ago. The distribution of seismicity indicates that the fault plane of the Futagawa segment is nearly vertical near the surface and northwest-dipping at depth. The Hinagu fault zone consists of the TakanoShirahata, Hinagu, and Yatsushiro Sea segments (Fig. 1b). The Takano-Shirahata segment has a long-term dextral slip rate of $0.04-0.2 \mathrm{~m} / \mathrm{kyr}$, and its latest event occurred 
1200-1600 years ago. The fault plane of the Takano-Shirahata segment is probably nearly vertical, because seismicity in 1999 and 2000 was distributed almost directly beneath the surface fault trace.

Active traces of the Futagawa and Hinagu fault zones were previously mapped on the basis of aerial photographs and field surveys by Ikeda et al. (2001), Nakata et al. (2001), and Nakata and Imaizumi (2002). In the Futagawa fault zone, right-lateral offsets of ridges and gullies were reported (Research Group for Active Faults of Japan 1991), and many tectonic features clearly indicate southside-up ground displacements (Ikeda et al. 2001). In the Hinagu fault zone, fault scarps in the Takano-Shirahata segment irregularly faced east or west along the disconnected fault trace, and in the Hinagu and Yatsushiro Sea segments fault traces are recognized as scarps clearly showing southeast-side-up displacement.

\section{Methods}

We mapped surface ruptures associated with the 2016 Kumamoto earthquake sequence and measured their displacement using measuring tapes, leveling staffs, and handheld laser rangefinders. Here, we report slip measurements in terms of strike-slip and vertical components, because most of the surface ruptures had predominantly dextral strike-slip or vertical offsets with little extension. Only surface ruptures along the northeastern part of the Futagawa segment had a significant extensional component. Near the Takaki area on the Takano-Shirahata segment, we measured displacements twice (April 16 and 28) after the mainshock to assess possible afterslip.

In this urgent survey, we needed to survey over $34-\mathrm{km}$ long ruptures in short time. Because most of the ruptures appeared in inhabited areas, they were likely to be quickly erased by recovery works or weathering. We, therefore, decided to use a simple and primitive method for a measurement of displacement (Fig. 2) with an accuracy of $1 \mathrm{~cm}$. To avoid underestimation of strike-slip displacement, we carefully selected reference markers (i.e., roads, footpaths between paddy fields, walls) which were long enough $(20-30 \mathrm{~m})$ to cover the deformation zone (generally $<10 \mathrm{~m}$ ) (Fig. 2a). For measuring slip on normal faults, we selected artificial or natural piercing points and measured displacements consisting of lateral, vertical, and extensional components. If there is any warping deformation away from the fault trace, this method would underestimate the total slip. At some points accompanied with warping deformation, therefore, we obtained topographic profiles with a handheld laser rangefinder to consider the total deformation. The uncertainty of our data depends strongly on the reliability of the selected piercing points or markers; therefore, we employed only clear

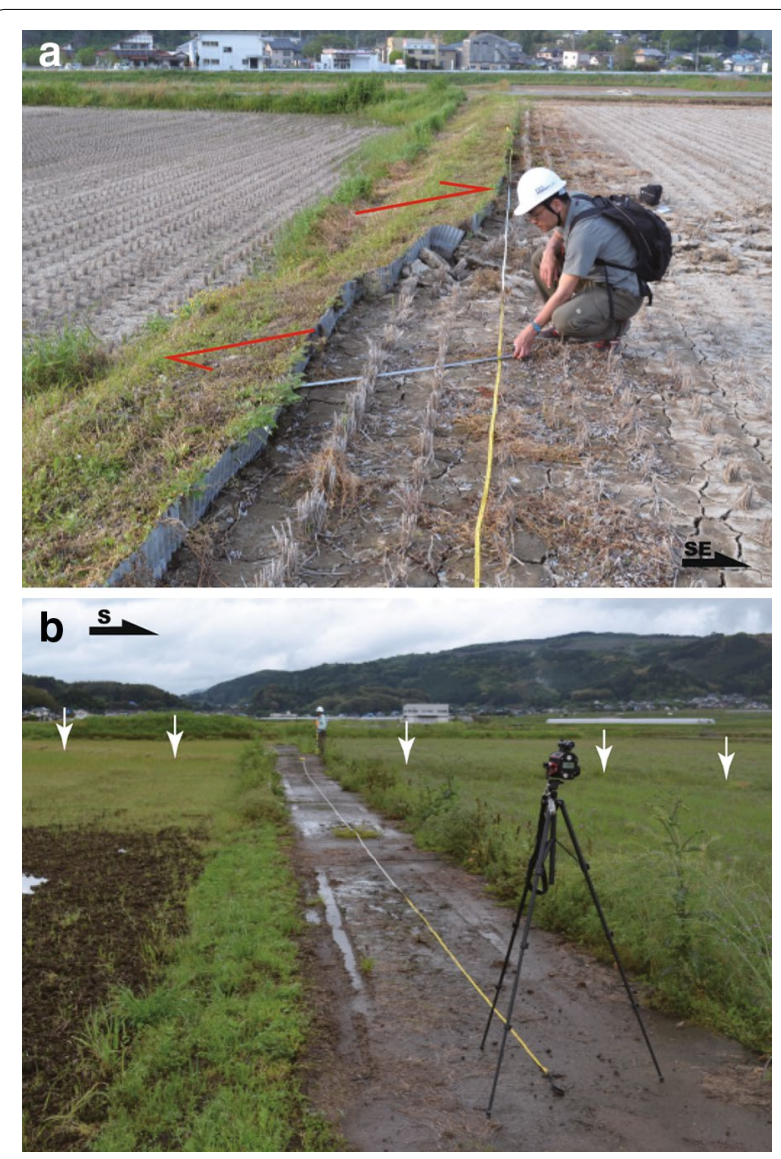

Fig. 2 a Measuring horizontal displacement. The grassy footpath in the paddy field was displaced dextrally (red half-arrows). b Measuring a cross section. The east side of the road in the paddy field was uplifted relative to the west side along the surface rupture (white arrows). A handheld laser rangefinder was used to construct a cross section along the line of the yellow measuring tape

and obvious reference points. We expect the uncertainty of our data as a whole would not exceed $\pm 10 \%$ of the total slip.

\section{Results}

Here, we describe the 2016 surface ruptures separately for the Takano-Shirahata segment of the Hinagu fault zone, the Uto segment of the Futagawa fault zone, and Futagawa segment of the Futagawa fault zone (Fig. 1b). Locations and photographs of these three areas are shown in Figs. 3-5, respectively. The measured slip distributions of the surface ruptures are compiled in Fig. 6 for all three areas. Original data to make Fig. 6 are compiled in Additional file 1 for right-lateral displacements along the Futagawa fault zone, Additional file 2 for right-lateral displacements along the Hinagu fault zone, and Additional file 3 for south-side-up displacements along the Futagawa fault zone. 


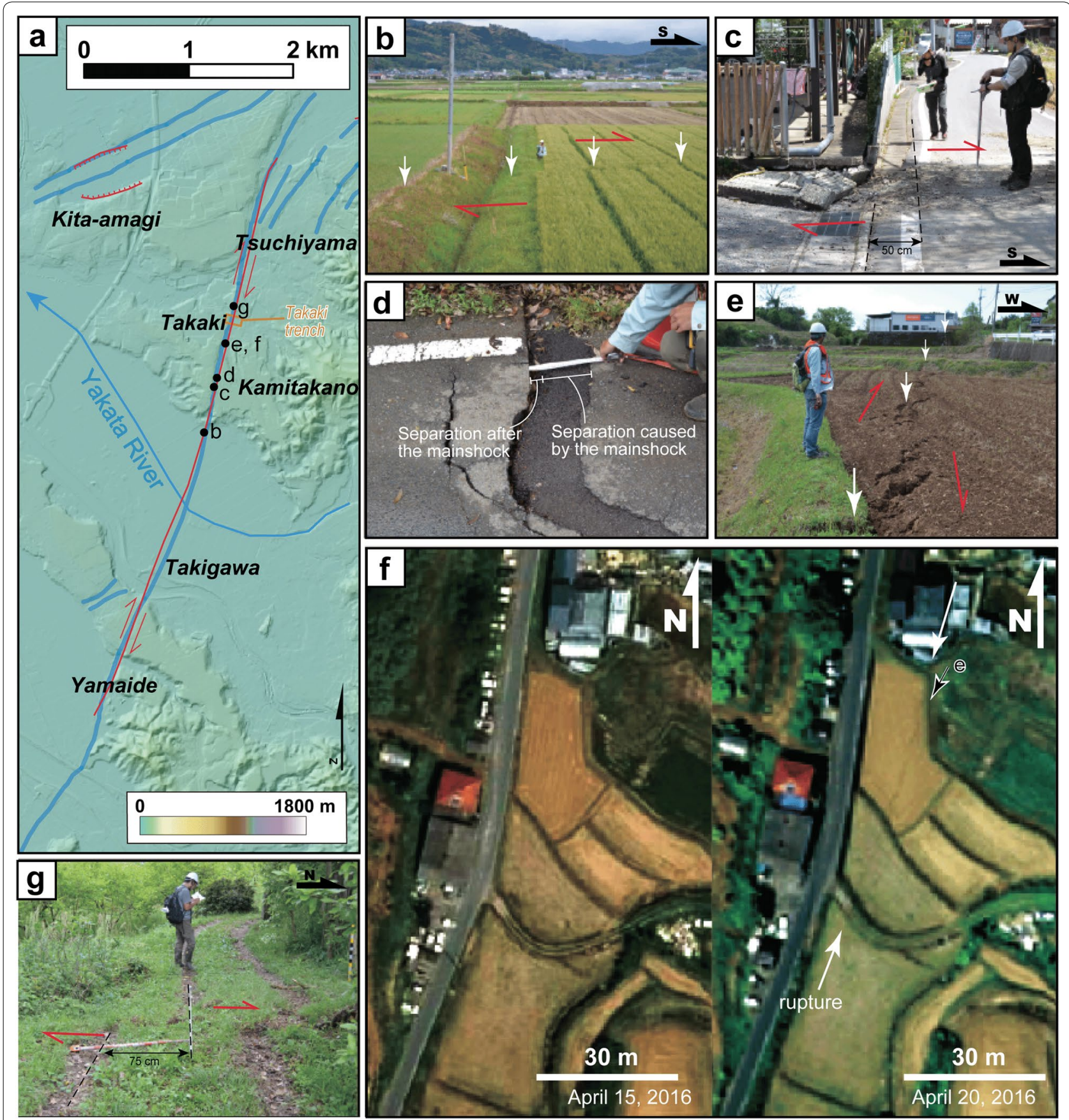

Fig. 3 a Distribution of surface ruptures (red lines), previously mapped active fault traces (blue lines), and locations of photographs (solid circles) and the trench site (yellow box) along the Takano-Shirahata segment of the Hinagu fault zone (Fig. 1c). b Cultural features including rows of wheat displaced dextrally (red half-arrows) at Kamitakano along the rupture (white arrows). c Edge of a road displaced dextrally. d Postseismic activity shown by a crack in a paved road at Takaki. The open crack, filled with asphalt after the mainshock, opened further by the time the photograph was taken on April 28. e Array of left-stepping tension cracks produced by dextral faulting in the alluvial plain at Takaki, as seen on April 16 after the mainshock. f Aerial photographs of Takaki (Geospatial Information Authority of Japan 2016a, b) on April 15 (left) and April 20 (right). No surface rupture was apparent on April 15, whereas a distinct surface rupture displacing rice paddies and footpaths was discernible on April 20. The black arrow shows the location of E. $\mathbf{g}$ Dextral offset of wheel tracks by $75 \mathrm{~cm}$ on a farm road in Takaki 


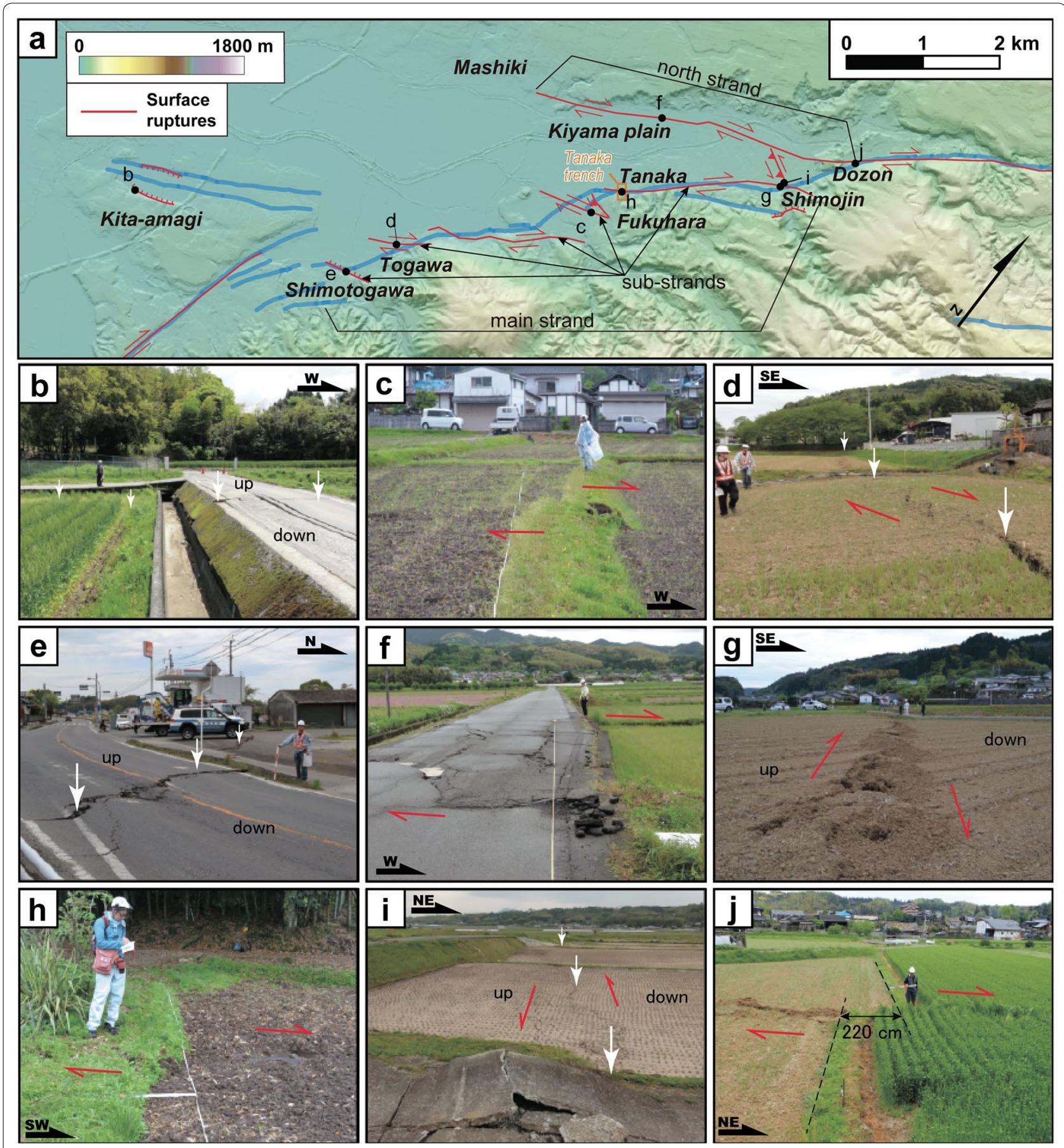

Fig. 4 a Distribution of surface ruptures, previously mapped fault traces, and location of photographs (black dots) and the trench survey (yellow box) in the Uto segment and the southwestern section of the Futagawa segment of the Futagawa fault zone (Fig. 1c). b Surface rupture (white arrows) across a road and paddy field at Kitaamagi. c Surface rupture at Fukuhara showing dextral displacement of footpath in a paddy field (red half-arrows). d Left-stepping tension cracks showing a dextral slip in a wheat field at Togawa. e Surface rupture across a road at Shimotogawa with the north side downthrown by normal faulting with little lateral slip. $\mathbf{f}$ Surface ruptures on the north side of the Kiyama plain showing dextral offset of a road and paddy field. $\mathbf{g}$ Tensional cracks and mole track at Shimojin. The northwestern side of the wheat field was locally upthrown. $\mathbf{h}$ Dextral displacement at Tanaka along a surface rupture consistent with a fault trace exposed in previous trenching. i Surface rupture with sinistral and reverse offset at Shimojin, connecting two left-stepping en echelon dextral ruptures on the northern and southern edges of the Kiyama River alluvial plain. j Dextral displacement of a wheat field at Dozon, where the maximum slip of $220 \mathrm{~cm}$ was measured 

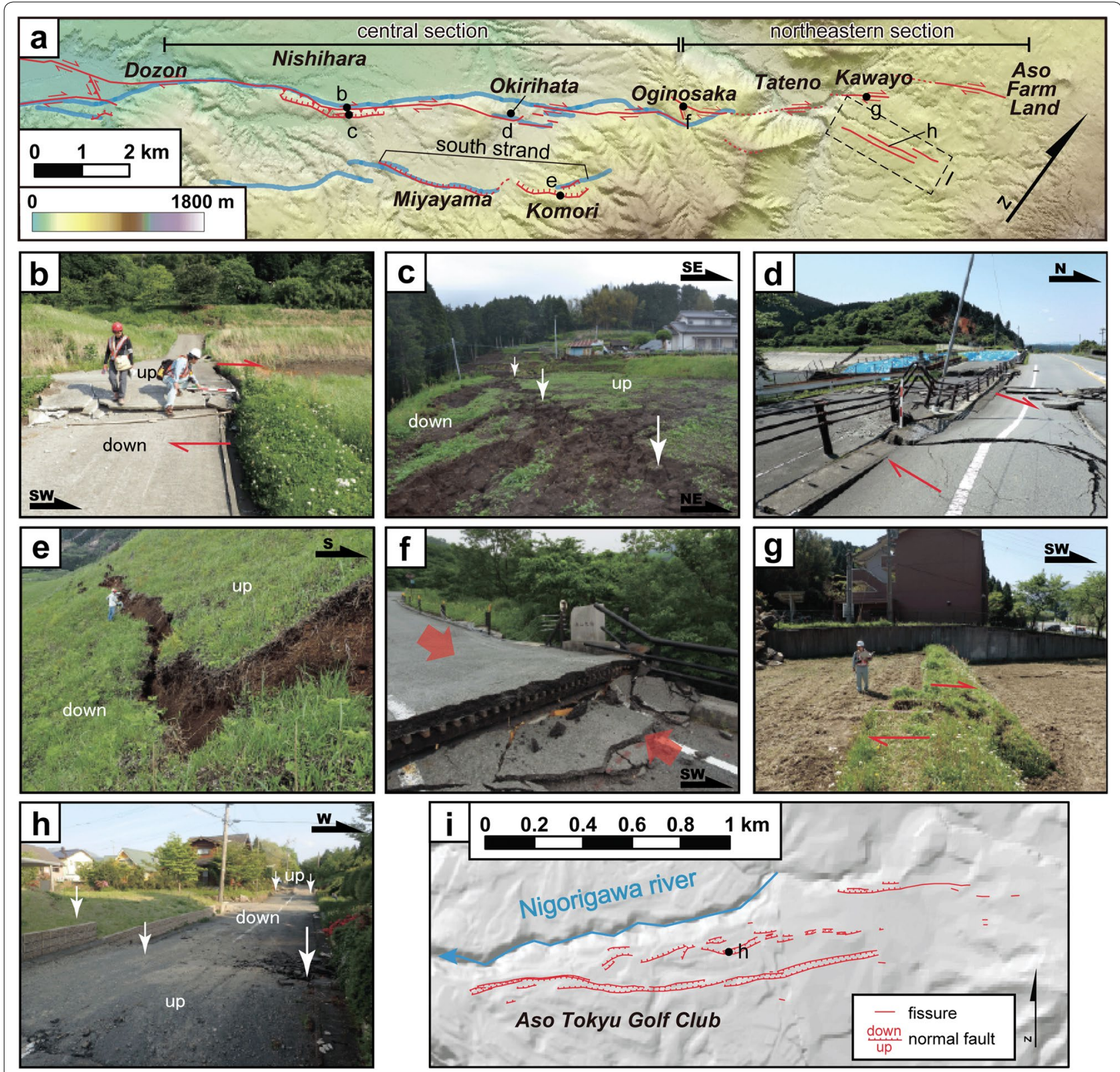

Fig. 5 a Distribution of surface ruptures, previously mapped fault traces, and location of photographs (black dots) in the central and northeastern sections of the Futagawa segment of the Futagawa fault zone (Fig. 1C). b Surface rupture (red half-arrows) crossing a road at Nishihara. South side was upthrown and displaced to the southwest by reverse and dextral faulting. c Array of left-stepping tension cracks (white arrows) south of Nishihara related to dextral and normal faulting on the hillside. $\mathbf{d}$ Surface rupture crossing a road at the Okirihata dam showing dextral slip. e Surface rupture at Komori with the north side downthrown by normal faulting. f Surface rupture crossing the bridge at Oginosaka which was compressed by dextral faulting (red arrows). $\mathbf{g}$ Surface ruptures at Kawayo showing dextral offset of a field and footpath. $\mathbf{h}$ A small graben crossing a road, defined by surface ruptures in the foreground and background. $\mathbf{i}$ Surface ruptures and fissures (red lines) near the Nigorigawa River that defined small grabens

\section{Takano-Shirahata segment}

Surface ruptures trending NNE-SSW appeared along $6 \mathrm{~km}$ of the northern part of the Takano-Shirahata segment of the Hinagu fault zone. It is noted that they directly coincided with previously recognized fault traces (Fig. 3a). Along this segment, the strikeslip component of displacement reached a maximum of 70-80 cm at Takaki (Figs. 3g, 6a) and gradually decreased with distance from Takaki to the north and south. 
Most ruptures in this segment were left-stepping en echelon arrays of open cracks with little vertical displacement (Fig. 3e), consistent with nearly pure right-lateral strike-slip. The southernmost ruptures, at Yamaide, displayed only a few centimeters of dextral slip. North of Takigawa, ruptures appeared in the alluvial plain on both sides of the Yakata River (Fig. 3b). At Kamitakano, roads, houses, and fields were systematically disrupted by $50-60 \mathrm{~cm}$ of dextral offset (Figs. 3c, 6a). In the Takaki area, ruptures in paddy fields coincided exactly with fault traces previously mapped by a paleoseismological survey (Shimokawa and Kinugasa 1999). North of Tsuchiyama, the surface ruptures scattered and then vanished.

Some residents at Takaki reported that only small cracks were present on April 15, the day after the initial $M_{\mathrm{J}} 6.5$ event, and that after the April 16 mainshock those cracks had grown, displaying more than $40 \mathrm{~cm}$ of dextral displacement. In addition, some researchers reported that no clear ruptures were present along the Futagawa and Hinagu fault zones on April 15 (Asia Air Survey Co. 2016). In aerial photographs of Takaki taken before and after the mainshock (Geospatial Information Authority of Japan 2016a, b), no surface rupture was apparent on April 15, but ruptures were clearly visible on April 20 (Fig. 3f). It is clear that surface ruptures along this section were mainly produced by the mainshock.

We also observed a temporal growth at Takaki. Our first measurements on April 16 indicated dextral displacements of about $50 \mathrm{~cm}$ (Fig. 3c), whereas our second measurements on April 28 indicated displacements of about $60 \mathrm{~cm}$. We also found that temporarily repaired cracks in a road crossing the surface rupture had opened further by April 28 (Fig. 3d).

\section{Uto segment}

At Kitaamagi, in the easternmost part of the Uto segment of the Futagawa fault zone, we documented two sets of ruptures trending ENE-WSW in an isolated area with 500$600 \mathrm{~m}$ long about $3 \mathrm{~km}$ from the nearest surface ruptures in the adjoining Futagawa segment (Fig. 4a). The southern rupture appeared along a preexisting north-facing fault scarp on the northern margin of the Kitaamagi upland (Ikeda et al. 2001; Fig. 4b), displaying approximately $30 \mathrm{~cm}$ of south-side-up normal offset and a small amount of dextral offset. A few hundred meters to the north, faint open cracks appeared near a previously mapped south-facing fault scarp.

\section{Futagawa segment}

Distinct surface ruptures extend about $28 \mathrm{~km}$ along the Futagawa segment between Mashiki and Minamiaso (Fig. 1c). We describe them here in three sections that are based on differences in morphology, geometry, and slip distribution of the surface ruptures.

\section{Southwestern section}

In the southwestern section of the Futagawa segment, most ruptures displayed $70-100 \mathrm{~cm}$ of dextral offset (Fig. 6a). Near Dozon, at the eastern end of this section, ruptures are composed of two strands that bound the Kiyama plain, a $5-\mathrm{km}$-long north strand along the northern edge and a 7-km-long main strand, along the southern edge of the plain (Fig. 4a). The main strand consisted of a left-stepping en echelon array of five substrands striking NE-SW. These sub-strands displayed dominantly dextral slip and south-side-up normal slip and were separated by releasing stepovers $1-2 \mathrm{~km}$ long and $0.5-1 \mathrm{~km}$ wide. This complex distribution of the substrands resulted in large scattering of measured displacements of the southwestern section (Fig. 6). The main strand ended just east of Shimojin, and the north strand continued eastward to the main strand in the adjoin central section. The north strand was a relatively continuous and displayed a few restraining double bends. Displacements on the two strands were largest $(90-120 \mathrm{~cm})$ at their northeastern tips, and systematically decreased toward the west (Fig. 6a). These two strands constituted a tweezers-shaped pair of splay faults, connected by a NWstriking sinistral-slip rupture near their closest approach (Fig. 4a, i). Most of the surface ruptures were accompanied by left-stepping en echelon arrays of open cracks associated with dextral faulting, sometimes with a small south-side-up normal component (Fig. 4c, d, f, g, h). At ruptures south of Shimojin and in Shimotogawa, the north side was downthrown $40-50 \mathrm{~cm}$ by normal faulting (Fig. 4e). Near Shimojin and Fukuhara, pairs of dextral ruptures striking NW-SE were connected by a rupture with sinistral and reverse offsets (Fig. 4a, i). The vertical and horizontal displacements on those sinistral ruptures both systematically decreased toward the northwest. The ruptures along the main strand nearly coincided with the previously recognized fault trace. The north strand was previously recognized as an active fault, Kiyama fault, only estimated by geological analyses of borehole cores (Tsuruta and Watanabe 1978).

\section{Central section}

In the central section of the Futagawa segment between Dozon and Oginosaka, the ruptures formed two strands: a 12-km-long main strand and a 4-km-long south strand 2-2.5 km away (Fig. 5a). The main strand displayed a large dextral slip of about $200 \mathrm{~cm}$ (Fig. 6a). At Dozon, we measured $220 \mathrm{~cm}$ of dextral displacement (Figs. 4j, 6a), the largest displacement on the 2016 surface ruptures. Along the main strand from Dozon past Nishihara, the rupture 


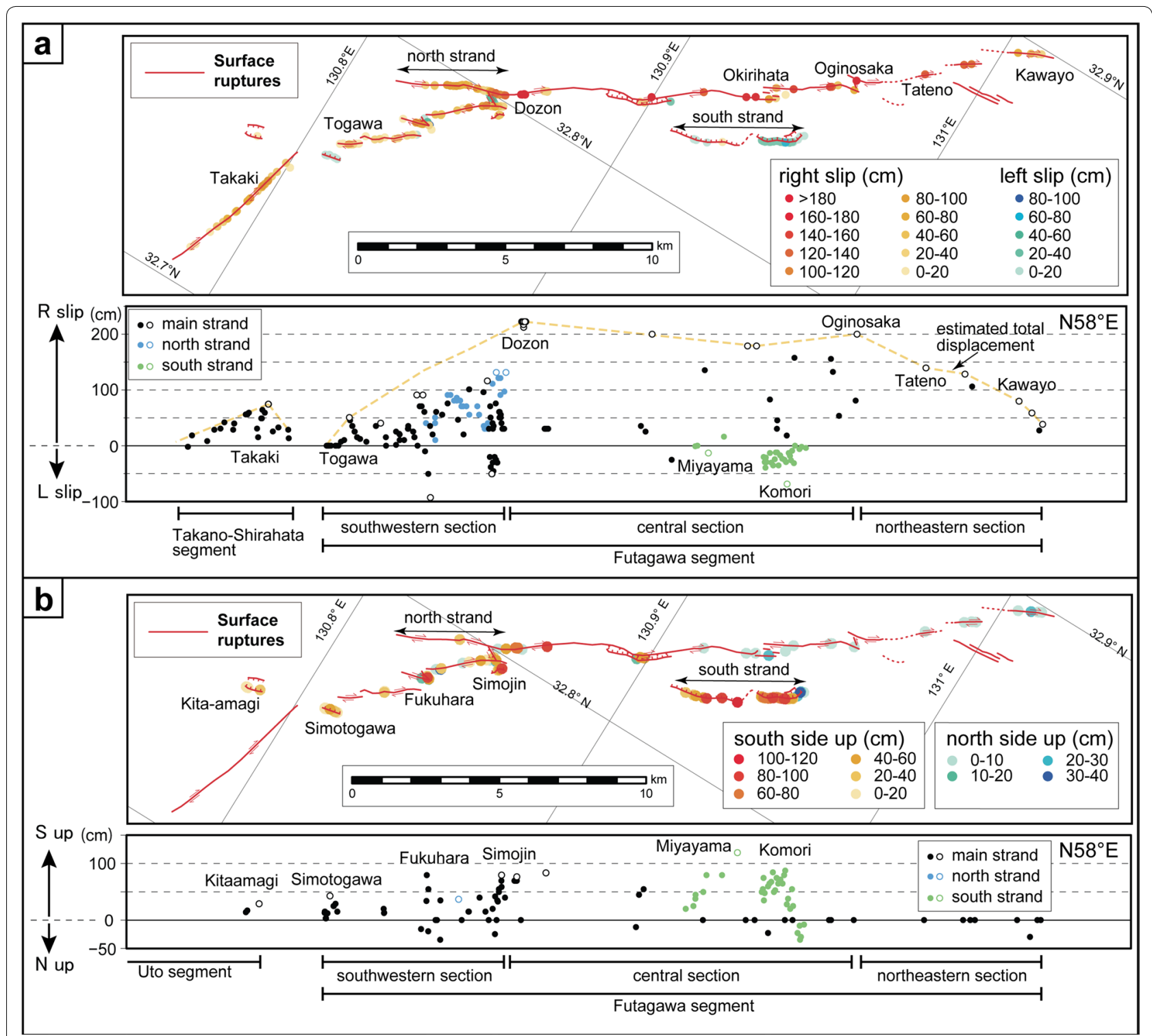

Fig. 6 a Distribution of the strike-slip component of surface ruptures (red lines) at measured locations (colored dots with the amount of displacement represented by their shade) along the Futagawa and Hinagu fault zones (top); explanation of surface ruptures in Fig. 1C. Diagram of slip distribution along the fault zone (bottom). Open dots show the representative displacement at each sub-strand. Dashed yellow line shows the estimated total displacement. b Distribution of the vertical component of surface ruptures along the Futagawa fault zone

followed a preexisting fault scarp several tens of meters high, and representing a fault zone $100-400 \mathrm{~m}$ wide. Normal fault ruptures formed a left-stepping en echelon array on the slope and shoulder of the preexisting scarp (Fig. 5c), and dextral-reverse fault ruptures appeared along the foot of the fault scarp with vertical slip up to $60 \mathrm{~cm}$ (Fig. 5b). Those arrays of ruptures suggest the existence of dextral slip along the rupture zone. A paved road crossing the rupture zone at very low angle in a counterclockwise direction to the general trend of the scarp was stretched about $200 \mathrm{~cm}$ in a 300-m-long part of the road. This feature of the damaged road was observed on strike-slip rupture associated with the 2000 Tottori-ken Seibu earthquake (Fusejima et al. 2001). This strongly suggests that the dextral slip of about $200 \mathrm{~cm}$ also occurred across the scarp.

Ruptures along the main strand continued eastward into the mountains and along talus slopes. The Okirihata dam was damaged by surface ruptures, and the banks of its impoundment on both sides of the dam were offset dextrally by $180 \mathrm{~cm}$ (Figs. 5d, 6a). The ruptures outlined a rhomboidal stepover $1.5 \mathrm{~km}$ long and $400 \mathrm{~m}$ wide located northeast of the dam. Father northeast, the ruptures 
intersected a road at several points where we measured about $150 \mathrm{~cm}$ of dextral fault slip.

In the central section, most dextral slip measurements were around $200 \mathrm{~cm}$, which is considered for a representative slip along the Futagawa segment. Some measurements less than $180 \mathrm{~cm}$ probably reflect the partial displacements on the rupture zone along the central section (Fig. 6a).

Whereas the main strand displayed little or no vertical displacement, ruptures on the south strand were dominated by southeast-side-up normal slip (Fig. 6b) along fault planes with measured dip angles between $50^{\circ}$ and $70^{\circ}$. These ruptures exhibited normal slip up to $120 \mathrm{~cm}$ (Fig. 5e), horizontal displacements in the dip direction up to $30 \mathrm{~cm}$, and sinistral strike-slip displacements up to $70 \mathrm{~cm}$ (Fig. 6). All along the 4-km-long ruptures were distinguished from ruptures associated with mass movement by their continuity across rivers and ridges. The combination of dextral offsets on the main strand and primarily normal offsets on the southern strand may represent large-scale slip partitioning, as reported by King et al. (2005) for the Kunlun fault. In that case, decreasing the dextral offsets with the distance from the main strand may produce relative sinistral motion on the south strand.

\section{Northeastern section}

Along the 8- $\mathrm{km}$-long northeastern section of the Futagawa segment, ruptures consisted of several en echelon arrays and gradually decreased in displacement toward the northeast (Figs. 5a, 6a). The central and northeastern sections were separated at Oginosaka by a stepover $2 \mathrm{~km}$ long and $1 \mathrm{~km}$ wide, connected by NW-striking ruptures with sinistral displacement, similar to stepovers described in the southwestern section near Shimojin and Fukuhara.

At Oginosaka, on the north side of the stepover, a rupture oriented ENE-WNW passed beneath a bridge oriented E-W, where about $200 \mathrm{~cm}$ of compression damaged the abutments (Fig. 5f). On the south side of the stepover, east of Oginosaka, an extensional branch rupture was observed in aerial photographs taken on April 16 (Geospatial Information Authority of Japan 2016c). From Tateno to the end of the rupture, three strands $1-2 \mathrm{~km}$ long constituted an en echelon array separated by releasing stepovers $100-500 \mathrm{~m}$ wide. The dextral displacement decreased along this array from $140 \mathrm{~cm}$ at Tateno and $120 \mathrm{~cm}$ at Kawayo (Fig. $5 \mathrm{~g}$ ) to $80 \mathrm{~cm}$ at Aso Farm Land and several centimeters at the eastern end (Fig. 6a).

Another E-W trending branch rupture $2.5 \mathrm{~km}$ long appeared south of Kawayo (Fig. 5a, i). This branch was a zone of sub-parallel fissures and grabens (Fig. 5h, i). Although much of the natural topography had been artificially modified, some of these grabens appeared to coincide with preexisting small valleys.

\section{Discussion \\ Morphology and geometry of surface ruptures}

The 2016 Kumamoto earthquake sequence produced about $34 \mathrm{~km}$ of surface ruptures. This discussion focuses on the $28-\mathrm{km}$ surface ruptures along the Futagawa segment of the Futagawa fault zone, which we divided into three sections on the basis of fault geometry and slip distributions.

The surface ruptures generally appeared along previously recognized fault traces, but did not always follow them precisely (Figs. 1c, 3a, 4a, 5a). Large dextral strikeslip displacements of about $200 \mathrm{~cm}$ occurred along the 12-km-long central section of the Futagawa segment, accompanied by significant normal slip in the middle part of the section. Surface ruptures of the southwestern and northeastern sections of the Futagawa segment were characterized by arrays of releasing stepovers $7-8 \mathrm{~km}$ long and $2.5 \mathrm{~km}$ wide that diverged toward the ends of the segment, unlike the continuous curvilinear traces that were previously mapped there (e.g., Ikeda et al. 2001) (Fig. 4a). Especially in the southwestern section, stepovers of the ruptures appeared where fault traces were indistinct in the previous fault maps. This reflects the difficulty of mapping active faults where their distribution is complex.

The most remarkable features of the 2016 surface rupture were the development of sub-parallel ruptures at various scales. Our observations showed that these sub-parallel ruptures accommodated coseismic slip by two different deformation styles, slip partitioning and graben formation. The most conspicuous slip partitioning was in the northeastern part of the central section of the Futagawa segment, where two sub-parallel primary ruptures formed $2-2.5 \mathrm{~km}$ apart (Fig. 5a). The southern rupture (south strand) displayed south-side-up normal slip greater than $100 \mathrm{~cm}$ with a small strike-slip component, whereas the northern rupture displayed dextral slip exceeding $150 \mathrm{~cm}$ with little or no vertical slip (Figs. 5d, 6a). Both of these ruptures occurred on previously mapped active fault traces (Nakata and Imaizumi 2002), suggesting that slip partitioning has been repeated during previous large earthquakes to form fault-related landforms. Grabens were especially prominent in the northeastern section of the Futagawa segment (Fig. 5i). Some of these had a distinct geomorphic expression suggestive of similar behavior in the past. Thus, to reconstruct the history of surface rupture in this area, paleoseismic trenching would be desirable because these grabens may preserve sedimentary evidence of past earthquakes. 


\section{Comparison with previous surveys}

The total surface rupture length of about $28 \mathrm{~km}$, the maximum slip of $220 \mathrm{~cm}$, and the mainshock magnitude of $M_{\mathrm{I}} 7.3$ are all broadly consistent with the fault length, slip, and earthquake magnitude assigned to the Futagawa segment by the ERC, HERP (2013) based upon the length of the segment. In addition, along the Futagawa segment, dextral slip of about $200 \mathrm{~cm}$ was measured throughout the central section, and slip gradually decreased bilaterally away from the central section to the far ends of the southwestern and northeastern sections. These lines of evidence strongly suggest that the April 16 mainshock was an example of the representative event anticipated for the Futagawa segment. On the other hand, the surface ruptures on the Takano-Shirahata segment of the Hinagu fault zone were only about $6 \mathrm{~km}$ long and were limited to its northernmost part. Understanding the implications of the 2016 Kumamoto earthquake sequence on the long-term behavior of the Takano-Shirahata segment will require further tectonic, geomorphic, and paleoseismic investigations.

Paleoseismic trenching studies were previously conducted at two sites where surface ruptures occurred in the 2016 Kumamoto earthquake sequence (Figs. 3a, 4a): the Takaki trench on the Takano-Shirahata segment (Shimokawa and Kinugasa 1999) and the Tanaka trench on the southwestern section of the Futagawa segment (Kumamoto Prefecture 1996; Yoshioka et al. 2007). Both trenches, excavated on the geomorphically distinct fault scarps suggestive of past faulting, exposed steeply dipping faults with evidence of Holocene faulting. Our field mapping revealed that surface ruptures around both sites lay along single traces and that locations of the ruptures coincided with the locations of the faults in the trench walls. This result shows that trenching can capture a history of multiple faulting when sites have been selected on the basis of sound tectonic and geomorphic interpretations.

The trenching survey at Tanaka revealed dextral $5.2 \mathrm{~m}$ displacement of sediment containing a volcanic ash (28 ka; AT tephra [Machida and Arai 2003)] along a fault trace (ERC, HERP 2013). At the location of the Tanaka trench, we measured $60 \mathrm{~cm}$ of dextral slip associated with the Kumamoto earthquake. To explain this accumulated displacement $(5.8 \mathrm{~m}), 9-10$ events similar to the 2016 earthquake are needed. Then, the recurrence period can be roughly estimated as about 3 kyrs.

\section{Temporal growth of surface ruptures}

Our observations and eyewitness account from the Takano-Shirahata segment, and the southwestern section of the Futagawa segment showed that small cracks associated with the initial $M_{\mathrm{J}} 6.5$ event on April 14 grew into primary ruptures with large slip during the mainshock. These observations were supported by interferometric synthetic aperture radar (InSAR) measurements (Fig. 7). Just after the initial event, widespread deformation was apparent at the west and northwest side of the Hinagu fault zone, but no significant deformation had occurred along the Futagawa and Hinagu fault zones (Geospatial Information Authority of Japan 2016d) (Fig. 7a). After the mainshock, major
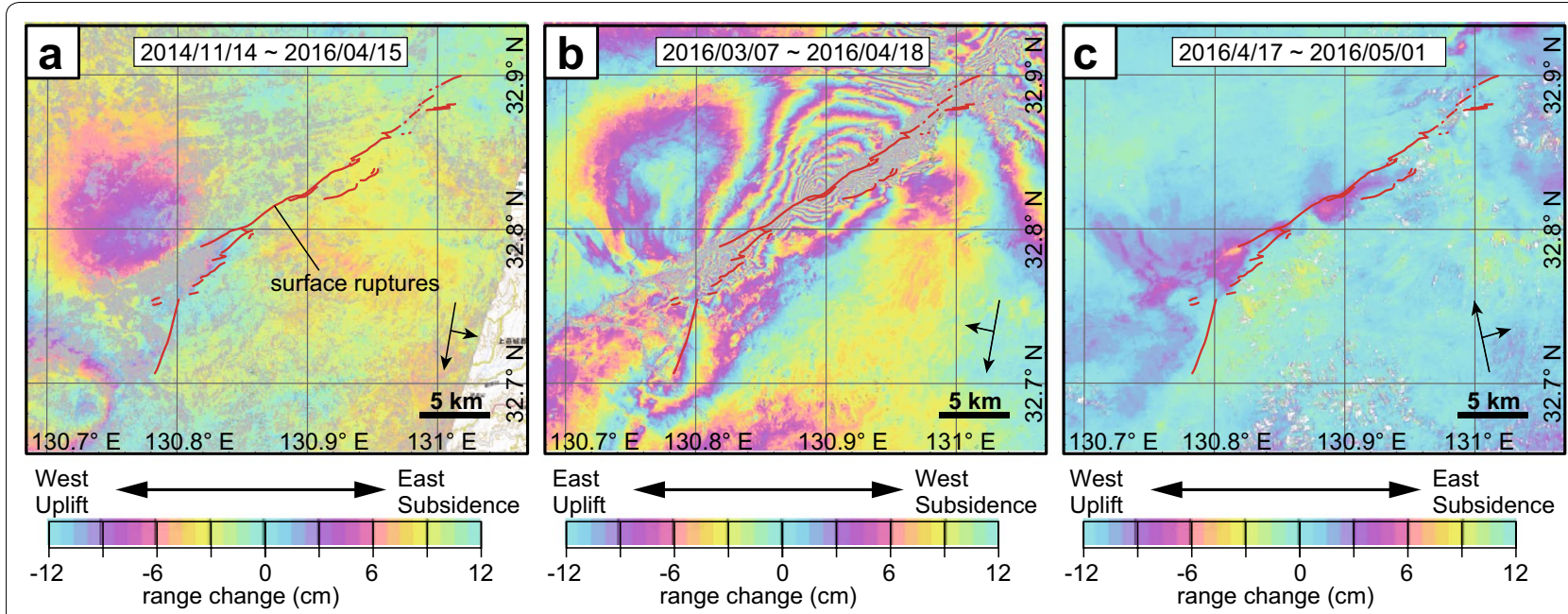

Fig. 7 InSAR images of the Kumamoto earthquake sequence with 2016 surface ruptures added (red lines). Analysis by Geospatial Information Authority of Japan from ALOS-2 raw data of JAXA. a InSAR image published just after the M, 6.5 event on April 14 (Geospatial Information Authority of Japan 2016d). b InSAR image published two days after the mainshock (Geospatial Information Authority of Japan 2016e). c InSAR image showing deformation during the 15 days after the mainshock (Geospatial Information Authority of Japan 2016f) 
slip had observed along these fault zones (Geospatial Information Authority of Japan 2016e) (Fig. 7b). We found evidence for further slip after the mainshock in the northern part of the Takano-Shirahata segment, where dextral slip of $50 \mathrm{~cm}$ as of April 16 had increased by $20 \%$ as of April 28, 12 days after the mainshock. Similar field observations were reported after the Napa earthquake of August 24, 2014 (Bray et al. 2014; Hudnut et al. 2014; Lienkaemper et al. 2016). In the case of Napa, afterslip amounted to $30-60 \%$ of the total slip. The temporal growth of surface ruptures associated with the Kumamoto earthquake were documented along both the Hinagu and Futagawa fault zones by geodetic surveys such as InSAR measurements (Fujiwara et al. 2016; Geospatial Information Authority of Japan 2016f) (Fig. 7c). These data suggest that when we measure the coseismic displacement, we need to survey in short time after the earthquake as our survey.

Detailed seismological observations have shown that the rupture plane of the mainshock differed from that of the initial $M_{\mathrm{J}} 6.5$ event, which was south of the junction of the Futagawa and Hinagu fault zones (e.g., Shimizu et al. 2016; Uchide et al. 2016; Fig. 1c). This means that large slip on the Takano-Shirahata segment coincided with slip from the mainshock on the rupture plane of the Futagawa segment. The surface ruptures around the junction between the two segments, therefore, may record seismic events generated by two different rupture planes at depth. The temporal changes in surficial slip may reflect the structural complexity around the junction of the Futagawa and Hinagu fault zones.

\section{Conclusions}

1. Surface ruptures occurred along $28 \mathrm{~km}$ of the Futagawa segment of the Futagawa fault zone, $6 \mathrm{~km}$ of the northern part of the Takano-Shirahata segment of the Hinagu fault zone, and $1 \mathrm{~km}$ of the eastern part of the Uto segment of the Futagawa fault zone.

2. Rupture zones generally consisted of left-stepping en echelon arrays of discontinuous fault traces of various lengths.

3. Along the Futagawa segment, dextral slip of about $200 \mathrm{~cm}$ was measured throughout the central section, and the slip gradually decreased bilaterally along the adjoining southwestern and northeastern sections.

4. Surface ruptures generally followed previously documented active fault traces, except in the northeastern and southwestern sections of the Futagawa segment.

5. Slip along the Takano-Shirahata segment occurred after both the initial $M_{\mathrm{J}} 6.5$ event and the mainshock, suggesting that surface ruptures along this segment may record seismic activity generated by two different rupture planes at depth.

\section{Additional files}

Additional file 1. Locations of surface ruptures along the Futagawa fault zone, where lateral displacements were measured. LON Longitude $\left({ }^{\circ} \mathrm{E}\right)$, LAT latitude $\left({ }^{\circ} \mathrm{N}\right)$, DATE measuring date, TIME measuring time, $R$-slip measured lateral displacement $(\mathrm{cm})$, where positive and negative values mean rightand left-lateral displacements, respectively.

Additional file 2. Locations of surface ruptures along the Hinagu fault zone, where lateral displacements were measured. LON Longitude $\left({ }^{\circ} E\right)$, LAT latitude ( $(N)$ ), DATE measuring date, TIME measuring time, R-slip measured lateral displacement $(\mathrm{cm})$, where positive and negative values mean rightand left-lateral displacements, respectively.

Additional file 3. Locations of surface ruptures along the Futagawa fault zone, where vertical displacements were measured. LON Longitude ( $\left.{ }^{\circ} \mathrm{E}\right)$, LAT latitude ( $\left.{ }^{\circ} \mathrm{N}\right)$, DATE measuring date, TIME measuring time, South-sideup measured vertical displacement $(\mathrm{cm})$, where positive and negative values mean south- and north-side-up vertical displacements, respectively.

\section{Authors' contributions}

All authors did the fieldwork. YS compiled all the data, drafted most of the manuscript and drew all the figures. YA and TM drafted part of the manuscript. YS, MY, YA, TM, TA, YM, KI, TO, MO, AM, and HM discussed the results and commented on the manuscript. All authors read and approved the final manuscript.

\section{Authors' information}

HM did the fieldwork as a member of the Geological Survey of Japan, AIST, and moved to Shinshu University on June 1, 2016.

\section{Author details}

${ }^{1}$ Geological Survey of Japan, National Institute of Advanced Industrial Science and Technology, 1-1-1 Higashi, Tsukuba 305-8567, Japan. ${ }^{2}$ Faculty of Science, Shinshu University, 3-1-1 Asahi, Matsumoto, Nagano 390-8621, Japan.

\section{Acknowledgements}

We are grateful to Takashi Nakata (Hiroshima University), Hiroyuki Goto (Kyoto University), and Masashi Omata (PASCO Corporation) for providing useful information on surface ruptures during our survey. We especially thank local residents for permitting our access to their properties; many of them also gave information on surface ruptures from the 2016 Kumamoto earthquake sequence. We also thank Yuichi Sugiyama, Wang Yu, and anonymous reviewer for helpful comments and advice. We used hypocenters from the unified earthquake catalog of the Japan Meteorological Agency.

\section{Competing interests}

The authors declare that they have no competing interests.

\section{Availability of data and materials}

The measurement datasets supporting the conclusions of this article are available in the supplementary materials.

Received: 31 July 2016 Accepted: 29 October 2016

Published online: 24 November 2016

\section{References}

Asia Air Survey Co., Ltd. (2016) Aerial photos taken on 15 April. http://www. ajiko.co.jp/article/detail/ID56EDF7EZH/. Accessed 29 Sept 2016

Bray J, Cohen-Waeber J, Dawson T, Kishida T, Sitar N (2014) Geotechnical engineering reconnaissance of the August 24, 2014 M6 South Napa earthquake. Geotechnical Extreme Events Reconnaissance (GEER) Association Report Number GEER-037, doi:10.13140/2.1.1094.7844

Earthquake Research Committee, Headquarters for Earthquake Research Promotion (2013) Long-term evaluation of the Futagawa and Hinagu fault zones (2013 revision). 66 (in Japanese). http://www.jishin.go.jp/main/ chousa/13feb_chi_kyushu/k_11.pdf. Accessed 16 July 2016 
Earthquake Research Committee, Headquarters for Earthquake Research Promotion (2016a) Evaluation of the 2016 Kumamoto Earthquake (in Japanese). http://www.static.jishin.go.jp/resource/monthly/2016/2016_ kumamoto.pdf. Accessed 16 July 2016

Earthquake Research Committee, Headquarters for Earthquake Research Promotion (2016b) Evaluation of Earthquake in Kumamoto Region, Kumamoto Prefecture on April 16, 2016 (in Japanese). http://www. static.jishin.go.jp/resource/monthly/2016/2016_kumamoto_2.pdf. Accessed 16 July 2016

Fujiwara S, Yarai H, Kobayashi T, Morishita Y, Nakano T, Miyahara B, Nakai H, Miura Y, Ueshiba H, Kakiage Y, Une H (2016) Small-displacement linear surface ruptures of the 2016 Kumamoto earthquake sequence detected by ALOS-2 SAR interferometry. Earth Planets Space 68:160. doi:10.1186/ s40623-016-0534-x

Fusejima Y, Mizuno K, Shishikura M, Imura R, Komatsubara T, Sasaki T, Yoshioka T (2001) Surface ruptures associated with the 2000 Tottori-ken Seibu earthquake. Annu Rep Act Fault Paleoearthquake Res 1:1-26 (in Japanese)

Geospatial Information Authority of Japan (2016a) Orthoimages at Mashiki area, taken on 15 April. http://maps.gsi.go.jp/\#18/32.737249/130.795554/\&base= std\&ls=std\%7C_20160414kumamoto_0415dol1\&disp=11\&lcd=_2016041 4kumamoto 0420dol04\&vs=c1j0l0u0f0\&d=vl. Accessed 25 July 2016

Geospatial Information Authority of Japan (2016b) Orthoimages at Mifune area, taken on 20 April. http://maps.gsi.go.jp/\#18/32.737249/130.79555 4/\&base $=$ std\&ls=std\%7C_20160414kumamoto_0420dol04\&disp=11\& $\mathrm{lcd}=\_20160414 \mathrm{kumamoto}$ 0420dol04\&vs=c1j0l0u0f0\&d=vl. Accessed 25 July 2016

Geospatial Information Authority of Japan (2016c) Orthoimages at Nishihara area, taken on 16 April. http://maps.gsi.go.jp/\#14/32.874469/130.97016 $3 / \&$ base $=$ std $\& \mid s=s t d \% 7 C \_20160414$ kumamoto_0416dol4\&disp $=11 \& \mathrm{lc}$ $\mathrm{d}=$ 20160414kumamoto_0416dol4\&vs=c1j0l0u0f0\&d=vl. Accessed 27 July 2016

Geospatial Information Authority of Japan (2016d) InSAR images published on 15 April

Geospatial Information Authority of Japan (2016e) InSAR images published on 18 April

Geospatial Information Authority of Japan (2016f) InSAR images published on 3 May

http://maps.gsi.go.jp/\#11/32.678107/130.720139/\&ls=std\%7Curg ent earthquake_20160414kumamoto_20141114_20160415 u06|\&disp $=01 \& \mid \overline{c d}=$ urgent_earthquake_20160414kumam oto_20141114_20160415_u06l\&vs=c1j0l0u0f1\&d=vl. Accessed 29 Sept 2016

http://maps.gsi.go.jp/\#11/32.727798/130.841675/\&ls=std\%7Curg ent_earthquake_20160414kumamoto_20160307_20160418_ u07r\&disp $=01 \& \mid c d=$ urgent_earthquake_20160414kumam oto_20160307_20160418_u07r\&vs=c1j0l0u0f1\&d=vl. Accessed 29 Sept 2016

http://maps.gsi.go.jp/\#11/32.727798/130.841675/\&ls=std\%7Curg ent earthquake 20160414kumamoto_20160416_20160430 u03r\&disp=01\&lcd=urgent_earthquake_20160414kumam oto_20160418_20160502_u07r\&vs=c1j0|0u0f1\&d=vl Accessed 29 Sept 2016

http://www.hp1039.jishin.go.jp/danso/Kumamoto2Afrm.htm. Accessed 24 July 2016

Hudnut KW, Brocher TM, Prentice CS, Boatwright J, Brooks BA, Aagaard BT, Blair $J$, Fletcher JB, Erdem JE, Wicks CW, Murray JR, Fred FP, John L, Jerry S, David PS, Daniel JP, Suzanne H, Stephen D, Carla R, Brenda J, Rynn L, Anne MR, Timothy PM, Timothy ED, Gordon S, Ron SR, Craig G, Darren H, Todd E, Dan M, Don FH, Jonathan DB (2014) Key recovery factors for the August 24, 2014, South Napa earthquake. US Geol Surv Open-File Rept 1249:51
Ikeda Y, Nakata T, Kaneda H, Tajikara M, Takazawa S, Chida N (2001) Active fault map in urban area [Kumamoto]. GSI Tech. Rep. D.1-No.368 (in Japanese)

King G, Klinger Y, Bowman D, Tapponnier P (2005) Slip-Partitioned Surface Breaks For the Mw 7.82001 Kokoxili Earthquake, China. Bull Seismol Soc Am 95:731-738. doi:10.1785/0120040101

Kumamoto Prefecture (1996) Evaluation of the Futagawa and Tatsutayama fault zone (in Japanese)

Lienkaemper JJ, DeLong SB, Domrose CJ, Rosa CM (2016) Afterslip behavior following the 2014 M 6.0 South Napa Earthquake with implications for Afterslip forecasting on other seismogenic faults. Seismol Res Lett 87(3):609-619

Machida H, Arai F (2003) Atlas of tephra in and around Japan. University of Tokyo Press, Tokyo (in Japanese)

Nakata T, Imaizumi T (eds) (2002) Digital active fault map of Japan. University of Tokyo Press, Tokyo

Nakata T, Chida N, Kaneda H, Tajikara M, Takazawa S, Okada A (2001) Active fault map in urban area [Yatsushiro]. GSI Tech. Rep. D.1-No.388 (in Japanese)

Research Group for Active Faults of Japan (1991) Active faults in Japan: sheet maps and inventories (revised edition). University of Tokyo Press (in Japanese)

Shimizu H, lio Y, Sakai S, Okada T, Takahashi H, Watanabe T, Goto K, Ohkura T, Asano Y, Matsushima T, Yamashita Y, Nakamoto N, Miyazaki M, Matsumoto S, Aizawa K, Shito A, Uchida K, Miyamachi R, Kamizono M, Teguri Y, Miyamachi H, Nakao S, Yakiwara H, Hirano S, Ohzono M, Shiina T, Takada M, Ichiyanagi M, Yamaguchi T, Okada K, Kosuga M, Azuma R, Uchida N, Emoto K, Ohta Y, Kaida T, Kozono T, Suzuki S, Takagi R, Demachi T, Nakahara H, Nakayama T, Hirahara S, Matsuzawa T, Miura S, Yamamoto M, Iwasaki T, Hirata N, lidaka T, Kurashimo E, Kato A, Nakagawa S, Yamanaka Y, Ito T, Terakawa T, Maeda Y, Horikawa S, Matsuhiro K, Okuda T, Katao H, Kano Y, Miura T, Tsuda H, Muramoto T, Okubo M, Yamashina T, Ueno T (2016) Urgent joint seismic observation of the 2016 Kumamoto earthquakeSeismic activities and their background. In: Abstract of Japan Geoscience union meeting 2016, MIS34-02, Chiba, 22-26 May 2016

Shimokawa K, Kinugasa Y (1999) Paleoseismicity and activity study of the Hinagu fault system. Research in Fiscal Year 1998 Findings of Active Fault Survey Projects EQ/99/3:253-262 (in Japanese)

Tsuruta K, Watanabe K (1978) Active faults in the southeast area of the Kumamoto plain. J Kumamoto Geosci Assoc 58:2-4 (in Japanese)

Uchide T, Horikawa H, Nakai M, Matsushita R, Shigematsu N, Ando R, Imanishi K (2016) The 2016 Kumamoto-Oita earthquake sequence: Aftershock seismicity gap and dynamic triggering in volcanic area. Earth Planets Space. doi:10.1186/s40623-016-0556-4

Yoshioka T, Shintani K, lemura K, Miyawaki R (2007) Paleoseismicity of the Futagawa-Hinagu fault zone, central Kyushu, Japan. Annu Rep Active Fault Paleoearthquake Res 7:241-258 (in Japanese with English abstract)

\section{Submit your manuscript to a SpringerOpen ${ }^{\circ}$ journal and benefit from:}

- Convenient online submission

- Rigorous peer review

- Immediate publication on acceptance

- Open access: articles freely available online

- High visibility within the field

- Retaining the copyright to your article

Submit your next manuscript at springeropen.com 